mladen.rieger@ff.uni-lj.si

\title{
PREVOD NA POGLED (PRIMA VISTA) - OD POPESTRITVE KLASIČNEGA POUKA PREVAJANJA DO LAKMUSOVEGA PAPIRJA ZA PREVAJALSKE PROBLEME
}

\section{UVOD}

Študentke in študenti medjezikovnega posredovanja na Oddelku za prevajalstvo se s prevajanjem v nematerni jezik (L1-L2) srečajo prvič v tretjem letniku prve bolonjske stopnje. To pa ne pomeni, da so popolni prevajalski začetniki. Za njimi je prevajalska propedevtika, ki zajema predavanja in vaje (razumevanje besedil, prepoznavanje besedilnih vrst, predvsem pa povzemanje daljših besedil) in dva semestra prevajalskih vaj v materni jezik (L2-L1). A razkorak med znanim in novim je vseeno velik in zahteva drugačne pristope, prilagojeno progresijo, postavljanje ožjih didaktičnih ciljev, ki omogočajo hkratno razvijanje prevajalskih kompetenc in zagotavljajo jezikovno sprejemljivost prevodov, prevajalskih vaj pa ne spreminjajo v jezikovni pouk.

Na tej stopnji se najpogostejše napake pojavljajo na besedilni ravni kot bolj ali manj izražene jezikovne pomanjkljivosti na področju morfologije in skladnje, na pragmatični ravni, pogosto pri prevajanju kulturno specifičnih elementov, sledijo pa jim napake, ki izhajajo iz nerazumevanja ali neupoštevanja prevodnega naročila in se kažejo kot funkcijska (zato tudi vsebinska) neustreznost prevoda kot celote. Če za odpravo jezikovnih napak poskrbita tako jezikovni pouk kot prevajalske vaje, je analiza in odprava pragmatičnih oz. prevodnih napak v domeni prevajalskih vaj.

$\mathrm{V}$ članku želimo teoretično in empirično pokazati, da prevodne napake in funkcijsko neustrezni prevodi nastajajo tudi zaradi pomanjkljive ali celo izpuščene priprave na prevodni proces.

\section{PREVODNI PROCES IN VLOGA PREVODNO USMERJENE BESEDILNE ANALIZE}

V idealnem primeru prejme prevajalec od naročnika izhodiščno besedilo s spremljajočim prevodnim naročilom. Njegovo delo poteka tako, da prevodno naročilo in izhodiščno 
besedilo prebere, nato sledi besedilna analiza, ki jo pogojuje prevodno naročilo, opravi potrebne raziskave (slovarji, strokovna literatura, internet, ...), potem povzame ciljno besedilo, ga šele nato prevede in ustrezno oblikovanega pošlje naročniku. Naštete aktivnosti in njihova intenzivnost se spreminjata glede na izkušenost prevajalca in zahtevnost izhodiščnega besedila, vendar vsak, ki želi prevajati konstruktivno, potrebuje načrt, saj morajo prevajalke in prevajalci vedeti, kaj počnejo (Hönig 1997: 40).

Pri študentih prevajanja smo v zadnjih letih s pomočjo priloženega vprašalnika in z oddaljenim dostopom do uporabniškega monitorja opazovali potek prevajalskega procesa med testi in izpiti. Analiza je pokazala, da večina najprej odpre urejevalnik besedil, internetni brskalnik, spletni slovar, redkeje naložen slovar in vse pogosteje Google Prevajalec. Po uvodnem branju in redkih zaznamkih v izhodiščnem besedilu (predvsem podčrtovanje) sledi neposredno prevajanje s pomočjo urejevalnika, drugih pripravljalnih faz ni zaznati. V študijskem letu 2009/10 so študenti po izpitnem roku odgovorili na vprašalnik o predpripravah. Nihče od anketiranih ni analiziral izhodiščnega besedila, kot najpogostejši razlog so navedli pomanjkanje časa.

Predvsem polprofesionalnim ${ }^{1}$ prevajalcem, to poimenovanje uporabljamo popolnoma nevtralno, torej nekomu, ki je na pol poti svoje izobraževalne kariere, nudi prevodno usmerjena besedilna analiza potreben metodološki okvir in smernice (načrt), ki zaradi ponovljivosti in preverljivosti na različnih besedilnih vrstah neizkušenemu prevajalcu posredujejo občutek varnosti in gradijo samozavest. Kautz (2002: 88) vidi zato največjo dodano vrednost besedilne analize pri pouku in doda, da lahko bodoči prevajalci z njeno pomočjo bolje razvijejo prevajalske kompetence kot pa s prevajanjem še tako velike količine besedil. Tudi Kußmaul (2007: 60) pripisuje pripravljalni fazi velik pomen, saj se prevajalec prav takrat odloča o morebitnih prilagajanjih izhodiščnega besedila ciljni kulturi.

Nord (2009) in Hönig (1997) zagovarjata primerljiv model besedilne analize. Prva ga približa prevodnemu procesu oz. postopku (übersetzungsrelevante Textanalyse), drugi prevajalcu (übersetzerrelevante Textanalyse), oba pa imata $\mathrm{v}$ mislih besedilno analizo kot predpripravo na prevajanje. Pri obeh poteka analiza na dveh ravneh, bodisi kot zunaj- in znotrajbesedilna analiza po Nordovi, ali pa kot makro- in mikroanaliza po Hönigu. Če se v prvi fazi prevajalka ali prevajalec sprašuje, ali je razumel/a izhodiščno besedilo, o njegovem učinku na ciljno publiko, komunikativni funkciji, členitvi besedila, o tem, kako bi izhodiščno besedilo delovalo na ciljnojezično publiko, če bi ne bilo kodirano $\mathrm{v}$ tujem jeziku, kaj povezuje s temo besedila in kakšne spremembe bi bile potrebne v ciljnem besedilu, dobi v drugi fazi odgovore na vprašanja kje, kdo, komu, čemu, kdaj, kako (s kakšnimi strukturami), zakaj in po katerem kanalu (prim. Hönig 1997: 55-56, Kautz 2002: 82-87, Nord 2009: 41-144).

1 V nemški prevodoslovni literaturi se je uveljavil izraz, ,semiprofessioneller Übersetzer“ za študentke in študente višjih semestrov. 
Za našo raziskavo je zanimiv model prevodnega procesa, ki ga je razvil Hönig (1997: 50-63) in poteka $v$ nadzorovanem (mikrostrategije) in nenadzorovanem (makrostrategije) delovnem prostoru. Polprofesionalni prevajalci se najraje gibljejo v nadzorovanem prostoru, ki ga razumemo kot kopičenje jezikovnih in prevajalskih pravil ter zakonitosti. Zanašanje izključno na mikrostrategije daje polprofesionalnemu prevajalcu občutek lažne varnosti, hkrati pa je vzrok prevajalčevih frustracij, saj se odločitve v nadzorovanem delovnem prostoru sprejemajo vse prej kot načrtno. V prevodnem procesu sicer pomembna samoevalvacija, ki zagotavlja, da se dobre prevodne rešitve ne izgubijo (Kußmaul 2007: 80), lahko, če temelji zgolj na naučenih pravilih in zakonitostih, deluje kontraproduktivno in zavira ustvarjalni proces. Polprofesionalni prevajalci v labirintu mikrostrategij (prim. Hönig 1997: 50) neustrezne prevodne rešitve pogosto posplošijo, ustrezne ali celo kreativne $^{2}$ pa zavržejo. Pomemben didaktični cilj prevajalskih vaj v nematerni jezik, kjer je odvisnost od pravil in zakonitosti večja, je usmerjanje študentk in študentov k makroanalizi, torej proti nenadzorovanemu delovnemu prostoru in šele v naslednji fazi približevanje nadzorovanemu delovnemu prostoru. Pri prevajanju, kot piše Hönig (ibid.: 50), namreč ne obstajajo absolutna pravila in zakonitosti, le relativno uporabna.

V nenadzorovanem delovnem prostoru si prevajalec nadzorovano postavlja vprašanja, ki smo jih opisali zgoraj kot prvo fazo prevodno usmerjene besedilne analize. Lahko bi jo poimenovali tudi kreativno razumevanje izhodiščnega besedila (prim. Kußmaul 2007: 60-70), kjer s pomočjo prizorov (scenes) in okvirov (frames) ter t. i. top-down-procesov ${ }^{3}$ fokusiramo osnutek ciljnega besedila. $Z$ metaforo prizorov in okvirov se naslanjamo na semantično šolo, ki pravi, da je naš dolgoročni spomin organiziran v obliki uokvirjenih mentalnih podob, pri čemer je prehod med prizorom in okvirjem tekoč. Z drugimi besedami, makroanaliza usmeri prevajalčevo pozornost na funkcionalen prevod, ki je skladen s prevodnim naročilom, hkrati pa omogoči ekonomično izrabo sredstev (čas) in prevajalskih pripomočkov (slovarji, strokovna pomoč, ...) Ker se omenjeni procesi odvijajo v nenadzorovanem delovnem prostoru, jih je nemogoče verbalizirati in empirično dokazati, lahko pa jih interpretiramo s pomočjo protokolov glasnega razmišljanja, tako da analiziramo zapis neposredno pred in po premorih (prim. Kußmaul 2007 in Hönig 1997). Za Höniga (1997: 58) je usvajanje in uporaba prevajalskih kompetenc odvisna prav od tega, kako so se prevajalke in prevajalci naučili delovati v nenadzorovanem in nadzorovanem delovnem prostoru in ali so sposobni usklajevati procese, ki jih generirata oba prostora. $\mathrm{V}$ svoji misli gre celo dlje in trdi (ibid.: 62), da lahko s pomočjo makrostrategije prevajalec prevaja tako dobro, kot mu to omogočajo njegove asociativne zmožnosti. Poudariti velja, da so prevajalske kompetence pridobljene, asociativne zmožnosti pa prirojene.

2 Kreativne prevajalske rešitve so nove, a hkrati smiselne, prilagojene realni situaciji ali uporabne (Kußmaul: 2007: 12).

3 „Top-down-procesi“ izhajajo iz že usvojenih védenj, spretnosti, vrednot in nazorov, ki vplivajo na razumevanje in interpretacijo izhodiščnega besedila. Pretok novih informacij od ciljnega besedila do prevajalca imenujemo „bottom-up-procesi“. 


\section{DIDAKTIČNI PRISTOP}

Prevodoslovje je imelo v preteklosti ambivalenten odnos do prevodne didaktike. Od tega, da se z didaktiko sploh ni ukvarjalo, ker je prioritetno gradilo lastno teoretsko podstat (prim. Kautz 2002: 138), preko zanikanja potencialnega razvoja splošnega prevodnodidaktičnega sistema (Wilss 1992: 186) in močno izražene skepse, da bi spodbude iskalo in našlo pri tujejezični didaktiki (ibid.: 188), pa vse do učinkovitih, funkcionalistično navdahnjenih pristopov, ki preizkušeno delujejo pri urah prevajanja (glej npr. Hönig in Kußmaul 1991, Kautz 2002, Nord 2009, Kußmaul 2010).

Če izhajamo iz prepričanja, da je vsak pedagoški izbor oseben (Dufeu 1996: 182) in da je naloga prevodne didaktike izbrati tiste izsledke prevodoslovja, ki bodo ugodno vplivali na sistematizacijo in strukturiranje prevajalčevega delovanja (Wilss 1992: 195) ter hkrati upoštevamo specifični jezikovni par (slovenščina - nemščina), bomo izbrali didaktične pristope, ki jih lahko podkrepimo s funkcionalistično teorijo prevajanja. Nemška funkcionalistična šola je ponudila največ didaktično uporabnih vsebin, ki spodbujajo in urijo različne prevajalske spretnosti (za posamezne spretnosti glej Kautz 2002: 142-143).

Prevajanje kot izrazito ciljno (produktno) naravnana dejavnost upravičeno narekuje ciljno usmerjen pouk, saj naj bi temeljil na dejanskem poteku prevajalskega ${ }^{4}$ procesa (ibid.: 138), vendar bi bilo neučinkovito, če bi pouk prevajanja - predvsem na vseh začetnih stopnjah, še posebej pa v nematerni jezik - omejili zgolj na izdelavo prevodov. Razvoj prevajalskih kompetenc lahko uspešno razvijamo le tako, da poudarimo prevajalski proces, to pa pomeni, da načrtno in ločeno utrjujemo posamezne spretnosti (za posamezne vaje glej ibid.: 159-267).

Ugotovili smo, da mora uspešna pedagoška praksa poleg ciljne naravnanosti upoštevati tudi prevajalski proces, ki ga lahko razložimo s pomočjo akcijsko usmerjenega pristopa kot ga pozna dramapedagogika. Za Tselikas (1999: 13) je dramapedagogika pristop, ki uporablja gledališka sredstva v pedagoški namen. V ospredje ne postavlja rezultata, torej produkcije gledališke igre, temveč proces učenja $\mathrm{v}$ vseh njegovih dimenzijah. Dramatičnost nastane, ko želja naleti na oviro, za uspešen razplet pa priskoči na pomoč neki tretji element. $Z$ malce domišljije lahko $v$ želji prepoznamo prevodno naročilo in marljivega prevajalca, ki se bori (ovira) z izhodiščnim besedilom tako, da upošteva vse zakonitosti makro- in mikroanalize, pri tem pa mu pomagajo prirojene asociativne zmožnosti. Za lažje premagovanje ovir mu priskočijo na pomoč prevajalski pripomočki, ki lahko med poukom oživijo in dobijo podobo učitelja ali sošolca s fakultete. Lahko pa razumemo vse tri elemente kot Dufeu (1996: 147) in dobimo zgodbo dveh mladih zaljubljencev iz Verone. Gledališko načelo rituala in rizika (prim. Tselikas 1999: 27) lahko enostavno prenesemo

4 Želimo razlikovati med prevodnim (prvo branje, besedilna analiza, izbira strategije, sinteza, ubeseditev v ciljnem jeziku) in prevajalskim (dodatno še: prvi stik z naročnikom, prevzem izhodiščnega besedila, morebitna predpriprava besedila za delo z urejevalnikom besedil, pogajanja o honorarju, priprava besedila za tisk, ...) procesom. 
v prevajalsko učilnico. Ritual bomo zapolnili z mikrostrategijami in ostalimi bottom-upprocesi in tako napolnili dvorano, a oder bo ostal še vedno prazen, dokler ga ne oživimo z makrostrategijami in top-down-procesi. Tselikas (ibid.: 28) primerja gledališko načelo rituala in rizika s procesom usvajanja tujega jezika, kjer se učenci prebijajo skozi zapletene oblikoslovne in skladenjske sisteme, torej rituale in pravila (prim. mikrostrategije pri procesu prevajanja), ki jim dajejo potreben občutek varnosti, hkrati pa želijo povedati nekaj novega, kreativnega in spontanega - torej tako, kot bi se pogovarjali v maternem jeziku (za posamezne drapapedagoške vaje pri pouku tujih jezikov glej Tselikas 1999: 57-134). Spontano in kreativno jezikovno delovanje predstavlja največji riziko v procesu usvajanja tujega jezika (prim. makrostrategije pri prevajanju). Pouk tujega jezika je uspešen, ko nam uspe povezati spontano izražanje z upoštevanjem jezikovnih pravil. Podobno velja za prevajanje. Usklajevanje makro- in mikroanalize izhodiščnega besedila je primerljivo s še enim gledališkim načelom, s paradoksom gledališke distance. Jennings (1998: 116) trdi, da se gledalec in igralec prav zaradi neresnične situacije, torej gledališke distance, zbližata, nazorneje se izrišejo teme, podobe, metafore in podpomeni. Pri prevajanju poskrbi za distanco prevodno naročilo, ki prevajalca „oddalji“ od izhodiščnega besedila in avtorja, da bi ga z ustrezno prevodno usmerjeno besedilno analizo in izbiro primernih makrostrategij približalo funkcionalnemu prevodu. Če je v gledališkem prostoru pomembna spremenljivka režiser, postane pri funkcionalističnem pristopu k prevajanju to naročnik, saj postaneta izhodiščno besedilo in njegova funkcija spremenljiva glede na zahteve ciljne publike (Kocijančič Pokorn 2003: 154).

\section{RAZISKAVA}

Izhodišče raziskave temelji na Kußmaulovi (2007: 79) trditvi, da so lahko že procesi razumevanja prevodni procesi, rezultati besedilne analize pa pogosto že prevodi. Izbrana empirična metoda mora torej dokumentirati predvsem tisti del prevodnega procesa, ki se nanaša na nenadzorovani delovni prostor. Za opazovanje prevodnega procesa se je uveljavila metoda protokola glasnega razmišljanja, ki je izšla iz psihologije in jo Wilss (1992: 208) pojmuje kot postopek samokonfrontacije, seveda brez posega psihologa. Ker lahko med introspekcijo ubesedimo le zavestne procese, neposrednega opisa dogajanja $\mathrm{v}$ nenadzorovanem prostoru tako ne moremo pričakovati, lahko pa analiziramo vse, kar je bilo izgovorjeno neposredno pred in po premorih, ki nastajajo kot mentalne blokade, ko naletimo na prevajalski problem (prim. Kußmaul 2007: 71).

Drugo izhodišče je bilo didaktično motivirano in povzema načelo dramapedagogike, ki ponuja takšne vsebine, ki pri učečih se ustvarjajo jezikovne stiske (Sprachnotsituationen), rešljive z jezikovnim delovanjem (prim. Tselikas 1999: 29). Tak pristop nam je približal prevajalsko delo, ki ga imenujemo prevajanje na pogled (prima vista, 
Stegreif-Übersetzen), a smo ga prilagodili potrebam raziskave tako, da smo nalogi dodali izhodiščno branje izvirnika. Izbrana oblika dela omogoča postavitev restriktivnega časovnega okvira, ki poskusnim osebam povzroča časovno stisko in tako omogoča osredotočanje na prevodni proces, omeji moteče zunanje in notranje dejavnike, hkrati pa spodbuja scensko vizualizacijo, ki po Kußmaulovem (2007: 158) prepričanju ugodno vpliva na prevod.

Namen raziskave je z neobičajno obliko dela usmeriti prevajalčev fokus iz (ne)varnega nadzorovanega delovnega prostora $\mathrm{v}$ nenadzorovan prostor, kar bo pospešilo aktivacijo top-down-procesov. Zanima nas, ali bo poskusna oseba, kljub subjektivno težki nalogi, vseeno ustvarila sprejemljiv prevod in uspešno prepoznala večino kulturno specifičnih elementov v izhodiščnem besedilu.

\subsection{Metoda zapisovanja}

Za kasnejšo obdelavo podatkov protokola glasnega razmišljanja je potrebno izbrati metodo zapisovanja, ki omogoča prosti pretok informacij in korpusov med posameznimi sorodnimi vedami, ki lahko rezultate uporabijo za nadaljnje raziskave, ima jasno strukturirana pravila zapisovanja, je ekonomična in enoznačna, zapis mora biti hitro berljiv in ga je možno rekonstruirati s poznavanjem majhnega števila pravil, hkrati pa mora biti uporaben na različnih računalniških sistemih, ker ne zahteva posebnega formatiranja besedila in znakov (prim. Göpferich 2005: 4). Eden od transkripcijskih sistemov, ki ustreza zgornjim zahtevam je t. i. GAT (Gesprächsanalytisches Transkriptionssystem), ki se je uveljavil v nemškem raziskovalnem prostoru. GAT pozna osnovno in napredno sintakso (Basistranskript, Feintranskript), ki ju lahko po potrebi kombiniramo. Prednost sistema je natančnost zapisa, ki z minimalnimi tipografskimi sredstvi upošteva celo besedni naglas (akCENT, ak!CENT!), spremembe višine tona (prišel je?/,///;/.), podaljševanje vokalov $(j a:, j a::$ ) spremembe glasnosti in hitrosti govora $(<<a l 1>$ tole moram preveriti v slovarju>), čustva (<<presenečeno> brki so spet moderni? ?) in celo dolžino glasnega dihanja $(. h, \ldots h)$ (za natančna pravila glej Göpferich 2005). GAT ima izdelana tudi pravila citiranja, kar olajša delo v znanstvenih in strokovnih publikacijah. Njegova slabost je časovna intenzivnost, kar pa bi lahko označili kot splošno značilnost transkripcije govornih interakcij.

\subsection{Izvedba poskusa in zunanji dejavniki}

V protokolih glasnega razmišljanja je sodelovalo deset poskusnih oseb. V vseh primerih so bili udeleženi polprofesionalni prevajalci in prevajalke, torej s prevajalskimi, ne pa tudi tolmaškimi izkušnjami. Poskusne osebe so imele dobro tujejezično znanje (bralno razumevanje: $\mathrm{C} 1-\mathrm{C} 2$, pisno in ustno izraženje: $\mathrm{B} 2+-\mathrm{C} 1$ ), odlično znanje maternega jezika in primerljive prevajalske izkušnje, ki so jih pridobile med študijem 
prevajanja. Prevod je potekal v slovenščino, ki je bila za osem oseb materni, za dve poskusni osebi pa nematerni jezik. Cilj raziskave ni bil preveriti jezikovne (ne)ustreznosti prevodov, temveč analizirati upoštevanje prevodnega naročila, prilagoditve izhodiščnega besedila in prepoznavanje kulturno specifičnih elementov. Posamezni protokoli glasnega razmišljanja so bili posneti z video napravo in kasneje transkribirani po metodi GAT. Med poskusom je bil na voljo osebni računalnik z elektronskimi slovarji in dostop do interneta. Slovarji v knjižni obliki zaradi postavljenega časovnega okvira niso bili na voljo.

Pred začetkom poskusa so poskusne osebe dobile naslednje prevodno naročilo: „Čez nekaj trenutkov boste sodelovali v preskusu protokola glasnega razmišljanja. Predstavljajte si, da ste zaposleni kot prevajalec/ka v nekem podjetju, kulturni ustanovi ali predstavništvu, kjer je čas in njegova učinkovita izraba vrednota. Med delovnim časom običajno samostojno prevajate in prevode oddajate v pisni obliki po elektronski pošti. Občasno pa dobite besedilo, ki ga morate ustno prevesti takoj. Imate približno 10-15 minut časa, da se pripravite. Od vas se pričakuje, da v ustni obliki predstavite funkcijsko prilagojen prevod. Lepo vas prosimo, da simulirate zgoraj opisano situacijo in pri tem vse vaše misli glasno verbalizirate. Cilj preskusa ni ocenjevati vaših prevajalskih rezultatov, temveč analiza razmišljanja med procesom prevajanja! Hvala za sodelovanje!"

Kriterij za izbor besedil pri pouku prevajanja mora med drugim upoštevati relevantnost besedila v ciljni kulturi, zato so npr. satirična besedila in podlistki manj primerni pri pouku prevajanja (Kautz 2002: 148-149), a smo se skladno z namenom poskusa načrtno odločili za gloso, ki tematizira večje število kulturno specifičnih elementov, besednih iger in okazionalizmov, in ki je sicer med poukom prevajanja ne bi ponudili. Zaradi značilnosti besedilne vrste, ki skriva poanto običajno na koncu, nas je zanimalo, če in kako bodo poskusne osebe funkcionalno prilagodile izhodiščno besedilo.

\subsection{Splošna analiza in interpretacija protokola}

Potek protokola glasnega razmišljanja lahko razdelimo na dva dela. V prvem delu poskusne osebe berejo izvirno besedilo, oblikujejo načrt dela, ugotavljajo prevajalske probleme in iščejo ustrezne prevodne rešitve, jih ocenjujejo, komentirajo prevajalsko delo in besedilo ter uporabljajo prevajalske pripomočke. V drugem delu prevladuje "čisti” prevod, pa tudi posamezni komentarji prevajalskega dela in besedila, celo ugotavljanje problemov pri prevajanju in ponovno branje izvirnika.

Osebe, katerih materni jezik je slovenščina, uporabljajo skoraj izključno ciljni jezik. Le redko ugotavljajo prevodne probleme zaradi ekvivalence, večino transkripta prvega dela predstavlja verbalizacija prevodnih rešitev, čustven odziv na ponujeno besedilo je majhen. Skupina je odkrila večino (75\%) kulturno specifičnih elementov in jih ustrezno razložila, vendar nihče od njih ni izpostavil avtorja, ki je v nemškem 
kulturnem prostoru splošno znan, njegov slog pisanja pa prepoznan. Visok odstotek prepoznanih kulturno specifičnih elementov dokazuje, da prevajalci z odličnim poznavanjem družbe in kulture izhodiščnega jezika uspešno tekmujejo s prevajalci, ki so materni govorci. Poskusne osebe iz te skupine so pri prevajanju pogosteje uporabljale funkcijske ustreznice, saj se zavedajo, da povprečen slovenski naslovnik nima natančnega vpogleda v nemški kulturni prostor.

Poskusni osebi, katerih materni jezik je nemščina, sta se naloge lotili sprva bolj sistematično. Začeli sta z glasnim interpretativnim branjem izvirnika, ki pa sta ga prekinjali z napovedjo in spremembo načina dela, pogosto sta se ustavljali in iskali slovenske ustreznice, tudi s pomočjo prevajalskih pripomočkov. Slovenščino uporabljata le, ko najdeta prevodno rešitev. Čustven odziv na besedilo je velik. V enem primeru so bili izpostavljeni vsi kulturno specifični elementi, drugič je ponovno manjkala omemba in vloga avtorja izvirnika. Povzetek oz. prevod na pogled je izražen v ciljnem jeziku z občasnimi ekskurzi v nemščini.

Največ napak je bilo zaradi neustreznosti prevoda. Izvirnik na satiričen način predstavi dva primera (prizor), ki nimata navidezno nikakršne povezave, nato pa ju s poanto (okvir) poveže v celoto. Za funkcijsko ustrezen prevod smo ocenili nesatirične povzetke:

- ki so upoštevali vpetost izvirnika v nemški kulturni prostor,

- ki so v uvodu opozorili na specifiko besedilne vrste in pisateljev slog,

- ki so v ospredje postavili povezovalno ključno misel (prizor), primera pa postavili ob rob (okvir).

Pričakovali smo torej, da bodo poskusne osebe izhodiščno besedilo ponovno uokvirile (Neurahmung) (prim. Kußmaul 2007: 166-158).

Vse poskusne osebe so ciljno besedilo sicer uspešno skrajšale in razložile kulturno specifične elemente med povzemanjem, vendar nihče povzetkov ni pospremil z ustreznim uvodom, ki bi olajšal razumevanje ciljnega besedila. Prav tako ni noben prevod ponudil ponovnega uokvirjanja. Zaključimo lahko, da so bili prevodi le delno funkcionalni, saj nihče ni opravil makroanalize izhodiščnega besedila, kar dokazujejo pogoste spremembe načrta dela in končni prevodi.

\subsection{Analiza in interpretacija izbranih delov protokola}

Poskusna oseba bere celotno besedilo tiho, pri tem neslišno premika ustnice. Že med prvim branjem poskuša simultano tolmačiti, vmes se ustavlja, občasno komentira, dokler ne pride do konca izhodiščnega besedila $(\rightarrow 11)$, naredi štiri daljše premore $(\rightarrow 11,12)$, nakar neposredno nadaljuje s končnim povzetkom $(\rightarrow 13)$. Protokol nam nazorno pokaže, da je makroanaliza izpuščena. Tudi če predpostavljamo, da ni bila verbalizirana, bi zanjo ostalo le 29 sekund. Poskusna oseba sicer zazna nujo po uvodu $(\rightarrow 13,14)$, vendar ga ne ubesedi dovolj natančno. 


\section{Primer 1:}

01 oke; <<tiho bere> (---)> mh; oke; <<tiho bere> (7.0)> skratka

02 bomo (--) besedilo je 0 : <<tiho bere> (4.0)> o brkih oziroma

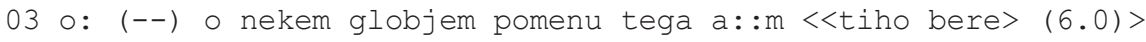

04 oke; $\langle\langle\mathrm{p}\rangle$ vodje razstave $(--)$ documenta $\rangle\langle<$ presenečeno $>$ ma

05 brke?> <<tiho bere> (8.0)> kar je po=politično-este: : (-) tska

$06<<$ tiho bere> (12.0)> oke; očitno so brki spet moderni e: :m

07 (.) kar označuje neko novo: (--) ero

( ( (..))

08 no in tle nam pove da on sam nosi: e brke že (---) od leta

09 tisoč devetsto sedeminsedemdeset (.) torej da (-) em (3.0)

10 očitno je zvest tem brkom <<all> ne glede na globalizacijo

--> 11 oziroma ne glede na to kaj je moderno in kaj ne> (5.0) zdaj pa

--> 12 recimo če bi celoten tekst (6.0) $<<$ p p povzela $>$ (13.0) oke; (5.0)

--> $13<<$ f> oke; zdaj celoten tekst se mi zdi zlo navezan na nemško

--> 14 kulturo zaradi treh tem (--) em najprej zaradi=zaradi voditelja

15 znane nemške televizijske oddaje

Preskočena besedilna analiza se lahko pokaže tudi kot pogosto spreminjanje oblike dela ali kot napovedane, a ne izvršene oblike dela $(\rightarrow 01,07)$. Poskusne osebe so bile sicer časovno omejene, vendar bi lahko z ustrezno makroanalizo natančno določile prevodne strategije in potreben čas za preverjanje v slovarjih ali na internetu (prim. Hönig: 1997: 89). Poskusna oseba se zaveda, da potrebuje načrt, ki bi ga morala določiti že na začetku prevodnega procesa, zato se k njemu vrača, ta pa se vse bolj oddaljuje. Oddaljevanje od načrta lahko opazimo tudi v pogosti rabi pogojnika, ki je zamenjal prihodnjik ( $\rightarrow 01,04,10)$. Diskusija o načrtu in izvedbi dela je celo sestavni del končnega prevoda oz. povzetka $(\rightarrow 10)$. V protokolih se potrdi Hönigova (ibid.: 57) teza, da prevajalčeve frustracije izhajajo iz zavedanja kompleksih mentalnih procesov pri prevajanju, ki pa se jim poskuša izogniti predvsem z zanašanjem na pravila (glej primer 3!).

\section{Primer 2:}

--> 01 ich werde mir jetzt schon während des lesens (-) die vokabel

02 aufschreiben

( ( (..))

03 wenn ich das ja nur äh kurz zusammenfasse so abschnittsmäßig

-->04 also (.) äh (.) der inhalt eines absatzes (-) den würd ich

05 wahrscheinlich in=in relativ einfachen worten dann (.)

06 wiedergeben

$((\ldots))$

-->07 ich würd mir jetzt wahrscheinlich stichworte machen nur noch

08 jeden absatz in=in nur noch vielleicht einen satz zu jedem

09 absatz schreiben damit ich die inhalte hab

( (...) )

--> 10 normalerweise wenn ich jetzt noch fünf minuten hätte würd ich

11 jetzt diese zeit nutzen um diese vokabeln nachzuschauen 
Omenili smo, da se polprofesionalni prevajalci radi zanašajo na pravila, ki so jih ponotranjili med izobraževalnim procesom. Pravila in zakonitosti, ki so del nadzorovanega delovnega prostora, pogosto posplošujejo, kar pa zavira ustvarjalni proces in interakcijo $\mathrm{z}$ nenadzorovanim delovnim prostorom. $\mathrm{V}$ našem primeru se je poskusna oseba naučila, da mora anglicizme, ki se sicer pogosto pojavljajo v njenem maternem jeziku (nemščini), zamenjati s slovenskimi ustreznicami $(\rightarrow 03)$. Posledica posplošenega pravila je mentalna blokada ne le pred anglicizmi, temveč pred vsako tujko v izhodiščnem besedilu.

\section{Primer 3:}

01 das mit dem ! DO!ping (.) ist auch wieder vokabel (-) schwierigkeit

02 wie man jetzt (4.0) doping auf slowenisch sagt keine

--> 03 ahnung=gerade bei diesen anglizismen wo man auf deutsch einfach

04 schön alles in neudeutsch irgendwie hat (-) ähm muss man sich

05 oft auf slowenisch irgendwie zu so einem spagat begeben dass man

06 ja (-) wie man da jetzt zu diesem englischen wort das man auf

07 deutsch so einfach verwendet (.) dann auf slowenisch sagt

Zanimiv je obraten primer: za besedo der Leiter (der Kunstausstellung Documenta) poskusna oseba spontano najde dve prevodni rešitvi. Oseba se je naučila, da vodja in voditelj v slovenščini nista zamenljiva, zato se refleks spremeni v refleksijo. Ker ni prepričana, katera rešitev je pravilna, se odloči za tretjo možnost - šef. Seveda bi bil umetniški vodja najustreznejši izraz, a poskus pokaže ustvarjalne poti iskanja prevodnih rešitev, ki jih ne ovirajo posplošena in ponotranjena pravila.

\section{Primer 4:}

01 ähm der leiter (.) ist das jetzt vodja oder voditelj?=<<rall>

02 das all diese schönen wörter wo ich dann nicht genau weiß was

03 angebracht ist> ähm !ŠEF! ich sag einfach nur šef

Poskusne osebe niso imele težav s prepoznavanjem kulturno specifičnih elementov v izhodiščnem besedilu ali s prenosom v ciljni jezik. Ugotavljale in komentirale so jih med prvim branjem $(\rightarrow 01,06)$ in $\mathrm{v}$ ustnem prevodu $(\rightarrow 11)$. Izpostaviti velja primer, ko poskusna oseba iz nemško govorečega prostora kot kulturno specifični element prepozna temo, ki bi jo prej prišteli splošni razgledanosti $(\rightarrow 17)$.

\section{Primer 5:}

--> 01 harald martenstein das ist doch der der diese kolumne hat da in 02 (--) was ist das die zeit (-) der (.) das mit dem zwiebelfischen 03 glaub ich der mit dieser sprachkolumne ja oke ähm

\section{Primer 6:}

04 no potem ko je bi:l (---) ko je pač pregledoval=ko je surfal po 05 internetu je zasledil (--) em komentar (---) michel friedmana, $-->06$ (--) em (-) to je: (---) ((kašelj)) (-) voditelj (--) em (.) 07 oziroma je bil (.) bivši voditelj talkshowa (--) $<<$ dim> 08 političnega (--) em v nemčiji> (2.0) to je pač treba razložit 
09 (.) tle jaz ne vidim neke primerjave z: :=s slovenskim kulturnim

10 prostorom

\section{Primer 7:}

--> 11 članek govori tudi o: : michelu friedmanu ki je znan em

12 televizijski voditelj i:n em o aferi: (---) dopinga ki se je

13 zgodilo pred leti e::m v kolesarstvu o=mislim da je bil

14 predvsem em tuki mišljen (--) nemška ekipa na touru de france

15 kjer je prišlo pač do priznanja ko je: em (-) kolesar priznal da

16 je=da je (-) jemal doping

\section{Primer 8:}

--> 17 die kunstausstellung documenta (.) das ist glaub ich in basel;

18 müsste ich später auch nachschauen vor allem das müsste man ja

19 vielleicht sowieso in einer slowenischen übersetzung erklären

20 (.) kamma nicht davon ausgehen dass das sofort jeder kennt ahm

V protokolih izstopa odziv poskusnih oseb ob besedi „Ukrainerinnen“. Tri poskusne osebe, ki prihajajo iz slovenskega kulturnega prostora, so besedo takoj povezale s pomenom prostitutke, čeprav prva omemba $v$ besedilu eksplicitno ne nakazuje te konotacije. Predvidevamo lahko, da imajo poskusne osebe dober vpogled v dnevno dogajanje $\mathrm{v}$ nemškem kulturnem prostoru, ali pa ima beseda $\mathrm{v}$ slovenskem prostoru močan asociativni naboj.

\section{Primer 9:}

01 njega so namreč $\mathrm{v}=\mathrm{v}$ hotel(-) ski so(.) bi od(-) kril s kokainom in 02 ukrajinskimi prostitutkami

Odziv poskusne osebe, ki prihaja iz nemško govorečega prostora, ni bi tako enoznačen:

\section{Primer 10:}

01 außerdem war da diese unschöne sache mit den ukrainerinnen?

03 <<presenečeno> den ukrainerinnen?=oje> (.) was hat der denn noch

04 angestellt dieser schlimme finger? das <<smejoče> weiß ich jetzt

05 gar nicht>

\section{SKLEP}

Prevajalske vaje, ki se osredotočajo predvsem na prevod, ne urijo vseh spretnosti, ki naredijo dobrega prevajalca. Predvsem na začetni stopnji prevajalskega izobraževanja moramo ponuditi takšne aktivnosti, ki bodo spodbujale posamezne prevajalske kompetence in samozavest. Poglavitni cilj prevodne didaktike je torej pokazati na mentalne procese, ki se odvijajo med prevajanjem in ponuditi vzvode, s katerimi jih lahko usmerjamo. 
Prevodno usmerjena besedilna analiza je poleg doživetega branja izvirnika prvi korak $\mathrm{k}$ funkcionalnemu in ustvarjalnemu prevodu. $Z$ njeno pomočjo lahko prevajalec uspešno usklajuje zavestne in nezavedne procese, izkoristi prirojen prevajalski potencial, določi načrt in predvidi časovne in organizacijske okvire.

V naši raziskavi, v kateri smo združili uveljavljeno empirično metodo protokola glasnega razmišljanja in metodo dela prevajanja na pogled, smo preverili, kako se polprofesionalni prevajalci znajdejo pri prevajanju kulturno specifičnih besedil v materni in nematerni jezik, ali pri tem upoštevajo rezultate besedilne analize in kako udejanjajo prevodno naročilo. Metodo prevajanja na pogled in protokol glasnega razmišljanja smo izbrali, ker smo prepričani, da lahko z njima zmanjšamo pomen nadzorovanega delovnega prostora in ker ju lahko z manjšimi prilagoditvami kasneje uporabimo pri pouku. Analiza raziskave je potrdila naša pričakovanja, da poskusne osebe ne bodo imele večjih težav pri prepoznavanju in pojasnjevanju kulturno specifičnih elementov, saj je pri takih nalogah transfer pridobljenih znanj pomembnejši od jezikovnih kompetenc. Zaključimo lahko, da je tip naloge spodbujal top-down-procese poskusnih oseb in jih motiviral za nadaljnje delo. Drugačne rezultate je pokazala analiza upoštevanja prevodnega naročila in besedilne analize. Vse poskusne osebe so ciljno besedilo skrajšale in $\mathrm{s}$ tem delno upoštevale spremenjeno funkcijo prevoda. Transkripti in končni povzetki pa so pokazali, da nihče ni izdelal ustrezne prevodno usmerjene besedilne analize. Zaradi izpuščene makroanalize so se poskusne osebe pri verbaliziranju svojega dela vedno znova vračale $\mathrm{k}$ načrtu dela, ga dopolnjevale in spreminjale ter ga tematizirale celo v povzetku. Sklepamo lahko, da se polprofesionalni prevajalci premalo zavedajo pomena predpriprave in da jih konvencionalne oblike prevajalskega pouka ne spodbujajo k poglobljenemu razmišljanju o svojem delu. Prevajanje na pogled in protokol glasnega razmišljanja sta sprožila samorefleksijo prevajalskega dela in poskrbela za občutek nelagodja, ki je bil posledica slabo opravljene predpriprave.

Upamo, da bodo rezultati raziskave spodbudili razpravo o delu in didaktičnih pristopih z začetniki ter spodbudili učitelje, da v svoje ure vključijo nekonvencionalne metode, ki bodo urile naslednje prevajalske spretnosti: prevodno usmerjeno besedilno analizo, razumevanje besedil in prepoznavanje in analizo besedilnih vrst. V študijskem letu 2014/15 bomo prilagojeno metodo prevoda na pogled in protokola glasnega razmišljanja vpeljali v redni pedagoški proces (prevajanje v nemščino) v obliki krajših pisnih osebnih protokolov, ki bodo spremljali vsak prevod. 


\section{LITERATURA}

DUFEU, Bernard (1996) Les approches non conventionelles des langues étrangères. Paris: Hachette.

GÖPFERICH, Susanne (2005) Praktische Handreichungen für Studien mit lautem Denken und Translog (2000 und 2006). http://www.susanne-goepferich.de/Handreichung.pdf (citirano 05.04.2013).

HÖNIG, Hans G./Paul KUßMAUL (1991) Strategie der Übersetzung: Ein Lehr- und Arbeitsbuch. Tübingen: Gunter Narr Verlag.

HÖNIG, Hans G. (1997) Konstruktives Übersetzen. 2. izd. Tübingen: Stauffenburg.

JENNINGS, Sue (1998) Introduction to Dramatherapy: Theatre and Healing. Ariadne's Ball of Thread. London in Philadelphia: Jessica Kingsley Publishers.

KAUTZ, Ulrich (2002) Handbuch Didaktik des Übersetzens und Dolmetschens. 2. izd. München: Iudicum Verlag.

KOCIJANČIČ POKORN, Nike (2003) Misliti prevod: Izbrana besedila iz teorije prevajanja od Cicerona do Derridaja. Ljubljana: Študentska založba.

KUßMAUL, Paul (2007) Kreatives Übersetzen. 2. izd. Tübingen: Stauffenberg.

KUßMAUL, Paul (2010) Verstehen und Übersetzen: Ein Lehr- und Arbeitsbuch. 2. izd. Tübingen: Narr.

NORD, Christiane (2009) Textanalyse und Übersetzen: Theoretische Grundlagen, Methoden und didaktische Anwendung einer übersetzungsrelevanten Textanalyse. 4. izd. Tübingen: Julius Groos Verlag.

TSELIKAS, Elektra I. (1999) Dramapädagogik im Sprachunterricht. Zürich: Orell Füssli Verlag.

WILSS, Wolfram (1992) Übersetzungsfertigkeit: Annäherungen an einen komplexen übersetzungspraktischen Begriff. Tübingen: Gunter Narr Verlag.

\section{ABSTRACT}

\section{Prima Vista Translation - From the Diversification of the Classical Teaching of Translating to the Litmus Paper for Translation Problems}

When students first become acquainted with translating, especially into non-mother tongue, the gap between the known and the unknown is large, demanding different approaches, adapted progress and the setting of narrower didactic objectives which enable the development of translation competences as well as ensure the linguistic admissability of translations, but at the same time do not turn the exercises in translation into linguistic studies.

Our survey which combined the well-established empirical method of the think-aloud protocol and the method of the prima vista translation aimed to examine how students find their way around translating culturally specific texts into their mother and non-mother tongue, whether they 
take into account the results of the textual analysis and how they put the translation order into practice. The analysis has shown that the tested persons managed to adequately identify the culturally specific elements and found culturally acceptable equivalents, but they produced functionally unacceptable translations due to the insufficient or left-out translation-targeted textual analysis.

Keywords: prima vista translation, think-aloud protocol, translation-targeted textual analysis, culturally specific texts

\section{POVZETEK}

\section{Prevod na pogled (prima vista) - od popestritve klasičnega pouka prevajanja do lakmusove- ga papirja za prevajalske probleme}

Ko se študenti/ke prvič srečajo s prevajanjem, še posebej v nematerni jezik, je razkorak med znanim in novim velik in zahteva drugačne pristope, prilagojeno progresijo, postavljanje ožjih didaktičnih ciljev, ki omogočajo hkratno razvijanje prevajalskih kompetenc in zagotavljajo jezikovno sprejemljivost prevodov, prevajalskih vaj pa ne spreminjajo v jezikovni pouk.

$\mathrm{V}$ naši raziskavi, v kateri smo združili uveljavljeno empirično metodo protokola glasnega razmišljanja in metodo dela prevajanja na pogled, smo preverili, kako se študenti/ke znajdejo pri prevajanju kulturno specifičnih besedil v materni in nematerni jezik, ali pri tem upoštevajo rezultate besedilne analize in kako udejanjajo prevodno naročilo. $Z$ analizo smo pokazali, da so poskusne osebe sicer ustrezno prepoznale kulturno specifične elemente in poiskale kulturne ustreznice, hkrati pa so zaradi pomanjkljive ali izpuščene prevodno usmerjene besedilne analize nastajali funkcijsko nesprejemljivi prevodi.

Ključne besede: prevod na pogled, protokol glasnega razmišljanja, prevodno usmerjena besedilna analiza, kulturno specifična besedila 